\title{
Effect of BMI and fat mass on HIV disease progression in HIV-infected, antiretroviral treatment-naïve adults in Botswana
}

\author{
S. S. Martinez ${ }^{1}$, A. Campa ${ }^{1}$, H. Bussmann ${ }^{2}$, S. Moyo ${ }^{2}$, J. Makhema ${ }^{2}$, F. G. Huffman ${ }^{1}$, O. D. Williams ${ }^{1}$, \\ M. $\operatorname{Essex}^{3}$, R. Marlink ${ }^{3}$ and M. K. Baum ${ }^{1 *}$ \\ ${ }^{1}$ Robert Stempel College of Public Health and Social Work, Florida International University, Miami, FL 33186, USA \\ ${ }^{2}$ Botswana Harvard AIDS Initiative Partnership, Gaborone, Botswana \\ ${ }^{3}$ Harvard School of Public Health, Boston, MA 02115, USA
}

(Submitted 14 August 2015 - Final revision received 8 January 2016 - Accepted 8 March 2016 - First published online 18 April 2016)

\section{Abstract}

An obesity paradox has been proposed in many conditions including HIV. Studies conducted to investigate obesity and its effect on HIV disease progression have been inconclusive and are lacking for African settings. This study investigated the relationship between overweight/ obesity (BMI $\geq 25 \mathrm{~kg} / \mathrm{m}^{2}$ ) and HIV disease progression in HIV+ asymptomatic adults not on antiretroviral treatment (ART) in Botswana over 18 months. A cohort study in asymptomatic, ART-naïve, HIV+ adults included 217 participants, 139 with BMI of $18 \cdot 0-24 \cdot 9 \mathrm{~kg} / \mathrm{m}^{2}$ and seventy-eight participants with BMI $\geq 25 \mathrm{~kg} / \mathrm{m}^{2}$. The primary outcome was time to event ( $\geq 25 \%$ decrease in cluster of differentiation 4 (CD 4 )

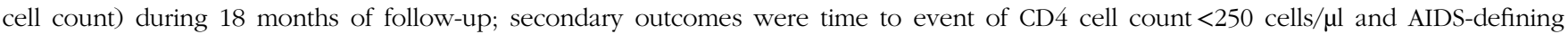
conditions. Proportional survival hazard models were used to compare hazard ratios (HR) on time to events of HIV disease progression over 18 months. Higher baseline BMI was associated with significantly lower risk of an AIDS-defining condition during the follow-up (HR 0.218; $95 \%$ CI $0.068,0.701 ; P=0.011$ ). Higher fat mass at baseline was also significantly associated with decreased risk of AIDS-defining conditions during the follow-up (HR 0.855; $95 \%$ CI $0.741,0.987 ; P=0.033$ ) and the combined outcome of having CD4 cell count $\leq 250 / \mu 1$ and AIDSdefining conditions, whichever occurred earlier (HR 0.918; $95 \%$ CI 0.847, 0.994; $P=0.036$ ). All models were adjusted for covariates. Higher BMI and fat mass among the HIV-infected, ART-naïve participants were associated with slower disease progression. Mechanistic research is needed to evaluate the association between BMI, fat mass and HIV disease progression.

\section{Key words: HIV infection: Antiretroviral treatment naïve adults: BMI: Disease progression: Body composition:} Bioelectrical impedance analyses

The importance of good nutrition in maintaining optimal health and delaying disease progression among HIV-infected patients has been documented in the literature ${ }^{(1,2)}$. At the beginning of the HIV epidemic, wasting was one of the main nutritionally related concerns; however, rates of obesity are now more common than the occurrence of wasting $^{(3-5)}$, particularly in patients on antiretroviral treatment (ART) ${ }^{(6)}$.

An obesity paradox has been proposed in many conditions including HIV infection, where those who are obese may have a survival advantage or improved disease outcomes ${ }^{(7)}$. The protective effect of obesity has been hypothesised to be related to extra available energy in the form of fat for use in times of crises, thus sparing protein use ${ }^{(8)}$, and also to help preserve the immune system response ${ }^{(9)}$. Studies on HIV and obesity have mainly been conducted in settings where patients are treated with ART, which may confound some of the findings and interpretations, as ART has been associated with lipodystrophy and obesity ${ }^{(5)}$. Although increased population obesity rates have been documented in countries with limited resources including those in Southern Africa ${ }^{(10)}$, studies on the relationship between HIV and obesity in African settings are lacking. It has been estimated that in sub-Saharan Africa, $10 \%$ of women have a $\mathrm{BMI} \leq 18.5 \mathrm{~kg} / \mathrm{m}^{2}$, with wasting still prevalent in some areas $^{(11)}$. However, the general population in sub-Saharan Africa is experiencing a nutrition-related transition with a rapid rise in being overweight and obese ${ }^{(12)}$.

Economic growth, urbanisation and diminished physical activity are contributing to the rise of obesity in Southern Africa $^{(13)}$. Studies of obesity and its effect on HIV disease progression have so far been inconclusive, with some reporting an association and others no association between cluster of differentiation 4 (CD4) cell counts and obesity ${ }^{(6,9,14-16)}$. Botswana is also experiencing an increase in overweight and obesity in the general population ${ }^{(17)}$. The prevalence of overweight/obesity in adult males is estimated to be $21 \cdot 5 / 5.8 \%$ and adult females $52 \cdot 6 / 24 \cdot 1 \%$, respectively ${ }^{(18)}$.

Abbreviations: ART, antiretroviral treatment; CD4, cluster of differentiation 4; CD8, cluster of differentiation 8; HR, hazard ratio.

* Corresponding author: M. K. Baum, fax +305 348 0383, email baumm@fiu.edu 
Botswana has one of the world's worst HIV epidemics, with a prevalence rate of $25 \cdot 2 \%$, among men and women aged 15-49 years $^{(19)}$, and it has been one of the first developing countries to provide universal access to $\mathrm{ART}^{(20)}$. Countries, especially in sub-Saharan Africa, however, are still facing many challenges in providing ART and maintaining adherence ${ }^{(21)}$. Therefore, having information on nutrition-related measures and their impact on delaying disease progression, in those regions where these two epidemics are co-occurring, is timely.

The objective of this study was to examine the relationship of overweight and obesity (BMI $\geq 25 \mathrm{~kg} / \mathrm{m}^{2}$ ) with HIV disease progression in HIV+ asymptomatic adults who were ART naïve and had CD 4 cell counts $>350$ cells/ $\mu$ l over 18 months in Botswana. The primary outcome for this subanalysis of a prospective study was time to the first occurrence of a $25 \%$ or greater decrease in CD 4 cell count during the course of the study, and the secondary outcomes were time to reaching CD 4 cell count $<250$ cells $/ \mu l$, AIDS-defining conditions and changes in HIV viral load.

\section{Methods}

\section{Study design and participants}

This study was a subanalysis of data from a prospective cohort study that included 219 HIV-seropositive men and women from the placebo group of a clinical trial of nutritional supplementation in Botswana. The parent study, from which the placebo group for the current observational study was drawn, was a multifactorial, randomised, double-blinded, placebocontrolled clinical trial, which investigated whether supplementation with multivitamins and Se could improve immune function and prolong time to AIDS in ART-naive, HIVseropositive adults ${ }^{(22)}$. The placebo group was used for this study to avoid any confounding effects from the micronutrient supplementation on the outcome measures. Participants were eligible for the parent study with documentation of HIVseropositive test results, CD 4 cell count $>350$ cells $/ \mu$ l, BMI $>18$ $\mathrm{kg} / \mathrm{m}^{2}$ for women and $>18.5 \mathrm{~kg} / \mathrm{m}^{2}$ for men, age $\geq 18$ years, not on ART, lack of a past history of AIDS-defining conditions or participation in another clinical trial. Women of child-bearing potential were tested for pregnancy before randomisation and were excluded if pregnant or became pregnant during the study. According to the current Botswana guidelines, HIV-seropositive adults receive ART when their CD4 cell counts are $<350$ cells $/ \mu \mathrm{l}$. The data for this study were collected between 2004 and 2009. When the parent study began recruitment, ART was initiated when the patient CD 4 cell count reached 200 cells/ $\mu$ l. Following the new guidelines, in March 2008, it was changed to 250 cells/ $\mu$ l. At this point, the changes were submitted to the respective Institutional Review Board (IRB) and funding agency, and the new outcome was adjusted statistically. All participants were recruited from the Botswana-Harvard AIDS Institute Partnership in Gaborone, Botswana. Participants received their medical follow-up in the same clinic where this study was conducted. The Florida International University IRB, the Harvard School of Public Health IRB and the Botswana Health Research Unit of the National Ministry of Health approved the study. Appropriate informed consent was obtained, and clinical research was conducted in accordance with guidelines for human experimentation as specified by the US Department of Health and Human Services and the researchers' institutions.

\section{Clinical data}

At baseline and every 3 months, physical examination was carried out and medical history was obtained by a trained nurse or a physician. Anthropometrics were obtained, and BMI was calculated by dividing the weight in kilograms by height in metres squared. Bioelectrical impedance analysis (BIA) using the Biodynamics body composition analyzer (model BIA-310; Biodynamics Corp.) was used to estimate fat and fat-free mass. Fat-free mass and fat mass are estimated with a regression equation based on data obtained through comparison between bioimpedance estimates with hydrodensitometry (Biodynamics, Inc.). The equation used was fat-free mass $=\left(a \times \mathrm{Ht}^{2}\right)+(b \times$ $\mathrm{Wt})+(c \times A)+(d \times R)+e$, where Ht is height in centimetres, Wt is weight in kilograms, $A$ is age in years and $R$ is impedance $(\Omega)$. The constants, $a$ through $e$, are proprietary information of Biodynamics, Inc. Electrodes were placed on the participant's right hand and wrist and right foot and ankle. Blood pressure was measured in the left arm with the elbow flexed to heart level. Subjects were measured without shoes and socks. Morbidity information including AIDS-defining conditions was assessed using questionnaires that were developed and validated by the Botswana-Harvard Partnership, and used in previous studies ${ }^{(23)}$, at screening and at every monthly visit, and confirmed by documentation in the medical chart. These questionnaires captured the diagnosis and/or signs and symptoms if they were detected during study visit. The date of onset and date of resolution if applicable were also recorded and confirmed by review of the medical chart.

\section{Laboratory data}

At baseline and every 3 months, blood samples were collected to determine CD4 and cluster of differentiation 8 (CD8) cell counts. Every 6 months, blood was also drawn to evaluate HIV-1 RNA load, as well as for a lipid panel and blood chemistry. Lymphocyte phenotype was determined using a fourcolour immunophenotyping panel of monoclonal antibodies. Differential counts were determined using a Coulter MaxM hematology instrument and corroborated with cytocentrifuge smears. HIV-1 RNA load was determined using an in vitro nucleic acid amplification test (Amplicor reagents and protocol; Roche Diagnostics).

\section{Nutritional data}

24 h-dietary recalls were collected at baseline and every 3 months by trained clinical staff. Macronutrient and fibre intakes were calculated using the NutriBase Professional, version 9 (Cybersoft) programme modified for the South Africa database, including native foods for which information was available. An average of at least three dietary recalls was used to obtain estimated energy, carbohydrate, protein, fat and fibre intakes. 


\section{Statistical analysis}

BMI was stratified into two groups: normal weight $(\mathrm{BMI}=$ $18.0-24.9 \mathrm{~kg} / \mathrm{m}^{2}$ ) and overweight/obese (BMI $\geq 25 \mathrm{~kg} / \mathrm{m}^{2}$ ). The overweight and obese BMI categories were combined to increase the sample size for the analyses. Laboratory markers of HIV infection and disease progression included in the analyses were absolute CD 4 cell count and CD4\% of total lymphocytes, absolute CD8 cell count and CD8\% of total lymphocytes, CD4: CD8 ratio and HIV-1 RNA load. Descriptive statistics including frequencies, percentages, medians and interquartile ranges were used to characterise the study variables (primary and secondary outcomes) at baseline and the differences between the two BMI groups. Mann-Whitney $U$ and $\chi^{2}$ tests were used to determine differences in HIV disease progression and markers of nutritional status between the BMI groups and by sex. Linear and logistic regressions at baseline and 18 months were conducted to observe the relationship between BMI and HIV disease progression and body composition measures from BIA using BMI as a continuous and dichotomous variable. Variance inflation factors (VIF) were used to check for multicollinearity. All models had a VIF $<5$; therefore, multicollinearity did not affect the results. Proportional survival hazard models were used to compare hazard ratios (HR) on time to events of HIV disease progression outcomes with BMI groups, with BMI as a continuous variable and with body composition over 18 months. The primary outcome for this subanalysis was time to the first occurrence of a $25 \%$ or greater decrease in CD4 cell count during the course of the study and secondary outcomes were time to CD 4 cell count $<250$ cells/ $\mu$ l, and AIDS-defining conditions. These events were documented from the time of inclusion into the study to the date of the visit in which the event was recorded. All models were adjusted for covariates. For all analyses, a two-sided test was used, and $P<0.05$ was considered to be statistically significant. Statistical analyses were carried out using SPSS version 21.

\section{Results}

\section{Demographics and clinical characteristics}

The parent study randomised 878 participants in four supplementation groups in a factorial design. For this longitudinal secondary analysis of data, we only analysed the placebo group, to prevent confounding our results with the use of active supplementation received by the other three arms of the parent study. A total of 219 participants were randomly assigned into a placebo group by the parent study ${ }^{(21)}$. Two participants had missing data and were excluded from the final analysis. In all, seventy-eight participants at baseline had $\mathrm{BMI} \geq 25 \mathrm{~kg} / \mathrm{m}^{2}$ and 139 had BMI of $18.0-24.9 \mathrm{~kg} / \mathrm{m}^{2}$. Most of the participants were female $(75.1 \%)$ with a median age of 33 years, reflecting the characteristics of the epidemic in Botswana ${ }^{(24)}$. Almost half $(45.2 \%)$ of the participants had at least a secondary education level and most of them had children (85.7\%) (Table 1).

There were differences in demographic factors, serum lipids, glucose and blood pressure among the BMI groups. Those with $\mathrm{BMI} \geq 25 \mathrm{~kg} / \mathrm{m}^{2}$ were older and more likely female, married, had children, and had higher levels of total cholesterol, TAG, LDL-cholesterol, glucose and blood pressure (Table 1). There were no differences in laboratory markers of HIV infection at baseline between the BMI groups. Total dietary energy intake and physical activity were not statistically different between the BMI groups. BMI were stable throughout the 18 months of follow-up and did not statistically change within the normal and overweight/obese groups (Table 2).

\section{BMI, body composition and laboratory markers of HIV infection and disease progression}

Logistic regression analyses that compared the BMI groups at baseline, 18 months and the change between these visits in the laboratory markers of HIV infection and disease progression were conducted; however, no significant associations were found with markers of HIV disease progression.

Linear regressions were also conducted to compare the measures of HIV disease progression and BMI as a continuous variable at baseline, 18 months and the change between these visits (Table 3). The change in CD4\% between baseline and 18 months was significantly associated with BMI, showing that for every unit increase in BMI there was 0.214 increase in the difference in $\mathrm{CD} 4 \%(\beta 0.214 ; 95 \% \mathrm{CI} 0.051,0.376 ; P=0.011)$. The association between CD8 cell count and BMI at 18 months approached significance ( $\beta$ 0.002; $95 \%$ CI 0.000, 0.004; $P=0.082$ ). All models were adjusted for age, sex, marriage and children.

Cox proportional hazard model with BMI as a dependent variable showed that higher baseline BMI was associated with a significantly lower risk of having an AIDS-defining condition (HR 0.218; 95\% CI 0.068, 0.701; $P=0.011$ ), after adjusting for age, sex, marriage, children and baseline CD 4 cell count and viral load. Significant associations were not found between continuous BMI and $\geq 25 \%$ decline in CD 4 cell count, CD 4 cell count $\leq 250 / \mu \mathrm{l}$ and the combined outcome of CD 4 cell count $\leq 250 / \mu \mathrm{l}$ and/or AIDS-defining conditions, whichever occurred first. In addition, $\mathrm{BMI} \geq 25 \mathrm{~kg} / \mathrm{m}^{2}$ as compared with those with BMI of $18-24.9 \mathrm{~kg} / \mathrm{m}^{2}$ was also not found to have significant associations with the outcomes of $\geq 25 \%$ decline in CD 4 cell count (HR 0.744; 95\% CI 0.489, 1.113; P=0.166), CD4 cell count $\leq 250 / \mu \mathrm{l}$ (HR 1.021; 95\% CI 0.381, 2.740; $P=0.966)$, AIDS-defining conditions (HR 0.500; 95\% CI 0.047, 4.465; $P=0.500)$ and the combined outcome of CD4 cell count $\leq 250 / \mu \mathrm{l}$ and/or AIDS-defining conditions (HR 1.089; $95 \% \mathrm{CI}$ $0 \cdot 453,2 \cdot 619 ; P=0.849$ ) (Table 4).

Cox proportional hazard models showed that higher fat mass at baseline was significantly associated with a decreased risk of having an AIDS-defining condition (HR 0.855; 95\% CI 0.741, 0.987; $P=0.033$ ) and a decreased risk of the combined outcome of CD 4 cell count $\leq 250 / \mu \mathrm{l}$ and/or AIDS-defining conditions, whichever occurred first (HR 0.918; 95\% CI 0.847, 0.994; $P=0.036)$. A trend towards significance was seen with higher fat mass association with a lower risk of $25 \%$ decline in CD 4 cell count (HR 0.974; 95\% CI 0.945, 1.003; $P=0.083$ ) (Table 4).

\section{Sensitivity analyses}

Sensitivity analyses were performed to examine the effect of $\mathrm{BMI}$ with exclusion of the lower end of the normal BMI range 
Table 1. Demographic characteristics by BMI groups at baseline

(Medians and interquartile ranges (IQR), numbers and percentages)

\begin{tabular}{|c|c|c|c|c|c|c|c|}
\hline \multirow[b]{2}{*}{ Variables } & \multicolumn{2}{|c|}{ Total $(n 217)$} & \multicolumn{2}{|c|}{ BMI $18.0-24.9 \mathrm{~kg} / \mathrm{m}^{2}(n 139)$} & \multicolumn{2}{|c|}{$\mathrm{BMI} \geq 25 \mathrm{~kg} / \mathrm{m}^{2}(n 78)$} & \multirow[b]{2}{*}{$P$} \\
\hline & $n$ & $\%$ & $n$ & $\%$ & $n$ & $\%$ & \\
\hline Age (years) & \multirow{2}{*}{\multicolumn{2}{|c|}{33}} & & & & & $0.005^{\star}$ \\
\hline Median & & & \multicolumn{2}{|c|}{31} & \multicolumn{2}{|c|}{35} & \\
\hline IQR & \multirow{2}{*}{\multicolumn{2}{|c|}{$28-39$}} & \multirow{2}{*}{\multicolumn{2}{|c|}{ 28-38 }} & & & \\
\hline Sex & & & & & & & \\
\hline Male & 54 & 24.9 & 44 & 31.7 & 10 & $12 \cdot 8$ & $0.002^{*}$ \\
\hline Female & 163 & $75 \cdot 1$ & 95 & $68 \cdot 3$ & 68 & $87 \cdot 2$ & \\
\hline Marital status & & & & & & & \\
\hline Single & 124 & 59.0 & 86 & $65 \cdot 2$ & 38 & $48 \cdot 7$ & $0.010^{*}$ \\
\hline Married & 24 & 11.4 & 9 & 6.8 & 15 & $19 \cdot 2$ & \\
\hline Other & 62 & 29.5 & 37 & 28.0 & 25 & $32 \cdot 1$ & \\
\hline Education & & & & & & & \\
\hline None & 13 & $6 \cdot 2$ & 9 & 6.8 & 4 & $5 \cdot 1$ & 0.984 \\
\hline Primary & 83 & 39.5 & 52 & 39.4 & 31 & $39 \cdot 7$ & \\
\hline Secondary & 95 & $45 \cdot 2$ & 59 & 44.7 & 36 & $46 \cdot 2$ & \\
\hline Tertiary & 19 & 9.0 & 12 & $9 \cdot 1$ & 7 & 9.0 & \\
\hline Monthly income & & & & & & & \\
\hline None & 48 & 22.9 & 17 & 21.8 & 31 & 23.5 & 0.804 \\
\hline$<300-600$ pula & 61 & $29 \cdot 0$ & 23 & 29.5 & 38 & 28.8 & \\
\hline $601-1000$ pula & 51 & $24 \cdot 3$ & 18 & $23 \cdot 1$ & 33 & $25 \cdot 0$ & \\
\hline $1001-6000$ pula & 43 & 20.5 & 16 & 20.5 & 27 & 20.5 & \\
\hline$>6000$ pula & 6 & 2.9 & 4 & $5 \cdot 1$ & 2 & 1.5 & \\
\hline Unsure & 1 & 0.5 & 0 & 0 & 1 & 0.8 & \\
\hline Children & & & & & & & $<0.001^{*}$ \\
\hline Yes & 180 & $85 \cdot 7$ & 107 & 81.1 & 73 & 93.6 & \\
\hline No & 30 & 14.3 & 25 & 18.9 & 5 & 6.4 & \\
\hline BMI $\left(\mathrm{kg} / \mathrm{m}^{2}\right)$ & & & & & & & $0.012^{*}$ \\
\hline Median & & & & & & & \\
\hline IQR & & & & & & & \\
\hline CD4 cell count (cells/ $/ \mathrm{l})$ & & & & & & & 0.908 \\
\hline Median & & & & & & & \\
\hline $\begin{array}{l}\text { IQR } \\
\text { CD8 cell count (cells/ } / \text { l) }\end{array}$ & & & & & & & 0.251 \\
\hline Median & & & & & & & \\
\hline IQR & 617 & 94.9 & & & & 7.8 & \\
\hline CD4:CD8 ratio & & & & & & & 0.375 \\
\hline $\begin{array}{l}\text { Median } \\
\text { IQR }\end{array}$ & & & & & & & \\
\hline IQR & & & & & & & 0.525 \\
\hline HIV viral load $\left(\log _{10}\right.$ copies $\left./ \mathrm{ml}\right)$ & & & & & & & 0.525 \\
\hline $\begin{array}{l}\text { Median } \\
\text { IQR }\end{array}$ & & & & & & & \\
\hline Total energy intake $(\mathrm{kJ})$ & & & & & & & 0.749 \\
\hline Median & & & & & & & \\
\hline IQR & 492 & 958 & & & & $10 \cdot 7$ & \\
\hline Total energy intake (kcal) & & & & & & & 0.749 \\
\hline Median & & & & & & & \\
\hline IQR & 117 & 902 & & & & 90.7 & \\
\hline Fat mass (\%) & & & & & & & $<0.001^{*}$ \\
\hline Median & & & & & & & \\
\hline IQR & & & & & & & \\
\hline Sports or physical activity & & & & & & & \\
\hline Yes & 168 & $80 \cdot 0$ & 109 & $80 \cdot 1$ & 59 & $79 \cdot 7$ & 0.942 \\
\hline No & 42 & $20 \cdot 0$ & 27 & 19.9 & 15 & $20 \cdot 3$ & \\
\hline Total cholesterol $(\mathrm{mmol} / \mathrm{l})$ & & & & & & & $<0.001^{*}$ \\
\hline Median & & & & & & & \\
\hline IQR & & & & & & & \\
\hline $\mathrm{TAG}(\mathrm{mmol} / \mathrm{l})$ & & & & & & & $<0.001^{*}$ \\
\hline $\begin{array}{l}\text { Median } \\
\text { IQR }\end{array}$ & & & & & & & \\
\hline $\mathrm{HDL}(\mathrm{mmol} / \mathrm{l})$ & & & & & & & 0.301 \\
\hline Median & & & & & & & \\
\hline IQR & & & & & & & \\
\hline $\mathrm{LDL}(\mathrm{mmol} / \mathrm{l})$ & & & & & & & $0.043^{*}$ \\
\hline Median & & & & & & & \\
\hline IQR & & & & & & & \\
\hline Glucose $(\mathrm{mmol} / \mathrm{l})$ & & & & & & & $0.002^{*}$ \\
\hline Median & & & & & & & \\
\hline IQR & & & & & & & \\
\hline Systolic blood pressure (mmHg) & & & & & & & $<0.001^{*}$ \\
\hline Median & & & & & & & \\
\hline IQR & & & & & & & \\
\hline Diastolic blood pressure $(\mathrm{mmHg})$ & & & & & & & $<0.001^{*}$ \\
\hline Median & & & & & & & \\
\hline
\end{tabular}

$\mathrm{CD} 4$, cluster of differentiation $4 ; \mathrm{CD} 8$, cluster of differentiation 8 .

* Statistically significant $(P<0.05)$.

† The currency in Botswana is pula and 1 pula was equivalent to about \$0.15-0.22 USD at the time the study was conducted. 
Table 2. Change in BMI $\left(\mathrm{kg} / \mathrm{m}^{2}\right)$ from baseline to 18 months by BMl groups (Medians and interquartile ranges (IQR))

\begin{tabular}{|c|c|c|c|c|c|}
\hline \multirow[b]{2}{*}{ Groups } & \multicolumn{2}{|c|}{ Baseline BMI } & \multicolumn{2}{|c|}{ 18-month BMI } & \multirow[b]{2}{*}{$P$} \\
\hline & Median & IQR & Median & IQR & \\
\hline Overall & $22 \cdot 8$ & $20 \cdot 7-27 \cdot 2$ & $24 \cdot 1$ & $20 \cdot 4-27 \cdot 2$ & 0.511 \\
\hline BMI $18.0-24.9 \mathrm{~kg} / \mathrm{m}^{2}$ & $21 \cdot 2$ & $19 \cdot 9-22 \cdot 6$ & $20 \cdot 9$ & $19 \cdot 3-22 \cdot 5$ & 0.338 \\
\hline $\mathrm{BMI} \geq 25 \mathrm{~kg} / \mathrm{m}^{2}$ & 28.5 & $26 \cdot 6-30 \cdot 1$ & $28 \cdot 1$ & $26 \cdot 1-30 \cdot 4$ & 0.466 \\
\hline
\end{tabular}

$\left(18-20 \mathrm{~kg} / \mathrm{m}^{2}\right)$ on measures of HIV disease progression. The Cox proportional hazard models were re-analysed excluding participants with BMI of $18-20 \mathrm{~kg} / \mathrm{m}^{2}$. BMI and fat mass no longer had significant associations with measures of HIV disease progression over 18 months. However, BMI $\geq 25 \mathrm{~kg} / \mathrm{m}^{2}$ was protective of the event combining the outcomes of CD 4 cell count $\leq 250 / \mu \mathrm{l}$, and/or AIDS-defining conditions (HR 0.219; $95 \%$ CI $0.055,0.873 ; P=0.031)$ when compared with BMI of $18-20 \mathrm{~kg} / \mathrm{m}^{2}$ after adjusting for age, sex, marriage, children and baseline CD 4 count and viral load.

\section{Discussion}

This study showed that higher baseline BMI and fat mass were associated with delaying the time to the first AIDS-defining condition in HIV-seropositive, ART-naïve adults in Botswana during 18 months of follow-up. Higher baseline BMI was associated with significantly lower risk of having an AIDSdefining condition. Higher fat mass at baseline was also significantly associated with a decreased risk of having AIDSdefining conditions and the combined outcome of having CD4 cell count $\leq 250 / \mu \mathrm{l}$ and/or AIDS-defining conditions, or whichever occurred earlier. These results are in agreement with the earlier observation by Shor-Posner et al. ${ }^{(9)}$ who found that obese study participants in Miami, FL, were significantly less likely to have a $25 \%$ decline in CD 4 cell count over 18 months. Wanke et al. ${ }^{(25)}$ also demonstrated that a past incidence of more than one AIDS-defining condition was associated with $1 \cdot 3$-fold risk of having $\mathrm{BMI}<20 \mathrm{~kg} / \mathrm{m}^{2}$, and AIDS-defining conditions were also associated with higher risk of wasting.

Higher BMI was also associated with a higher CD4\% after 18 months of follow-up. CD $4 \%$ is considered to provide better prognostic information before ART is initiated ${ }^{(26-28)}$. Other investigators have also found that immune counts are affected by weight and/or BMI in HIV-infected adults ${ }^{(14,29)}$. Crum-Cianflone et $a$. $^{(29)}$ compared normal weight adults with obese HIVseropositive adults at diagnosis and through highly active antiretroviral therapy (HAART) or ART initiation and concluded that those who were obese had smaller reductions in CD $4 \%$ through time, regardless of whether the diagnosis took place in the preHAART era or afterwards. Interestingly, Crum-Cianflone et al. ${ }^{(29)}$ also showed that weight did not have an effect on immune cells, including CD4 cell counts at HIV diagnosis, but instead the effect of weight on immune cells became more significant as the HIV disease progressed. Our study also did not find any significant differences in absolute CD 4 cell count or CD $4 \%$ at baseline between the normal-weight and overweight/obese groups,

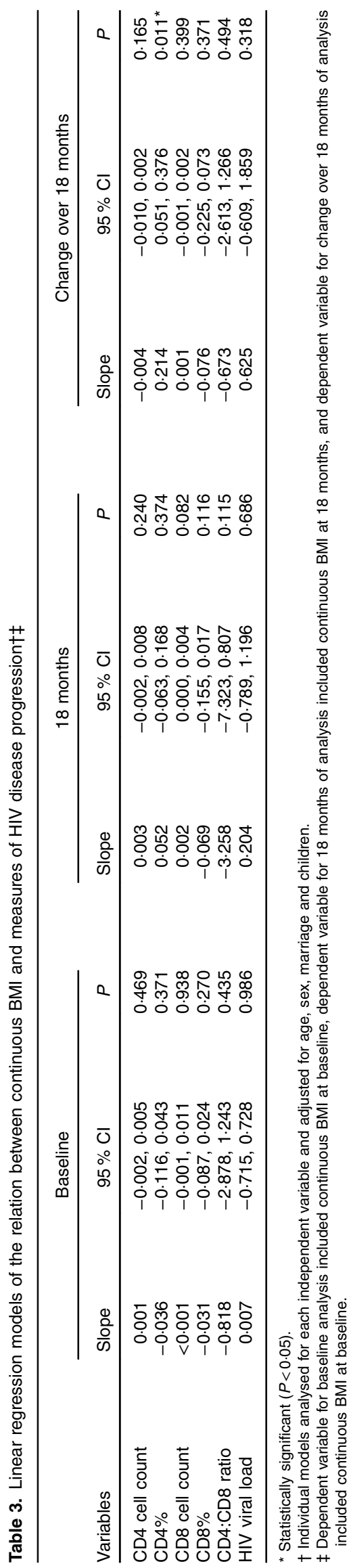


possibly because the participants were recruited relatively early in the disease.

This is the first study that demonstrated a longitudinal association between higher fat mass and lower risk of AIDS-defining conditions. Higher fat mass was associated with a lower risk of the combined outcome of CD 4 cell count $\leq 250 / \mu 1$ and/or AIDSdefining conditions, whichever occurred first. These findings are in agreement with previous cross-sectional studies that found that women with previous AIDS-defining conditions had lower total body fat ${ }^{(30)}$ and that BMI was positively associated with CD4 cell count among HIV-seropositive women, which was hypothesised to be due to excess fat ${ }^{(15)}$.

Although in the survival analysis a positive association between CD4 cell count and fat mass approached significance, our earlier cross-sectional analysis using the entire cohort ( $n$ 878) at baseline showed that this relationship was statistically significant ${ }^{(31)}$. Thus, our findings suggest that higher BMI and higher fat mass were associated with slower disease progression in ART-naïve, HIV-infected adults. We hypothesise that high HIV viral load and immune activation in patients who are not on ART are associated with a hypermetabolic state ${ }^{(32)}$ requiring additional energy ${ }^{(33,34)}$; thus, patients who are obese may have an advantage in maintaining and utilising fat stores to assist in preserving the immune system ${ }^{(16,35)}$. Moreover, recent research has shown that adipocyte-derived adipokines affect a range of cellular immune processes and may also be involved in preserving the $\mathrm{CD} 4$ cell count ${ }^{(36)}$. On the other hand, maintaining a large lean body mass has higher energy costs, and stored protein is less available and provides less energy than the same weight in fat ${ }^{(37)}$. Thus, this might explain why lean body mass was not protective in this cohort who were not on ART.

Interestingly, a recent study utilising data from 8381 participants in the North American AIDS Cohort Collaboration on Research Design has found that higher BMI (approximately $30 \mathrm{~kg} / \mathrm{m}^{2}$ ) and presumably higher amount of body fat at ART initiation was associated with greater CD4 cell recovery at 12 months, showing that the beneficial effect of higher BMI was largely preserved after the patients initiated $\mathrm{ART}^{(38)}$. However, once patients control their HIV viral load with ART, the energy requirements are most likely reduced and classic risk factors for chronic disease develop ${ }^{(39-42)}$. The participants of this study in the overweight/obese group had higher levels of total cholesterol, LDL-cholesterol, TAG, glucose and blood pressure, although the differences in these parameters were not clinically significant between the BMI groups. These differences could, over a period of time, potentially increase their risks for chronic conditions.

Stevens et al. ${ }^{(43)}$ have stated concerns over providing confusing messages when discussing the obesity paradox and the possible harm it will have on public health efforts related to reducing obesity rates to lower the risk of chronic diseases. Conversely, other researchers ${ }^{(44)}$ theorise that our view of normal or optimal weight or BMI categories are too strict and may be biologically unsuitable. In this study, a BMI of $18-20 \mathrm{~kg} / \mathrm{m}^{2}$, which is considered to be in the normal range, was still associated with HIV disease progression and may need to be further examined to see whether for HIV infection a shift in the BMI categories might be more appropriate. They also argue that those with an established disease diagnosis may benefit from an 
emphasis on lifestyle recommendations regarding physical activity and nutrition rather than intentional weight loss or gain. Important nutritional elements to consider for people living with HIV may include medication-nutrition interactions, barriers to maintenance and restoration of nutritional status, food and water safety, food security issues and evaluation of interactions with alcohol and illicit drugs ${ }^{(45)}$.

The strengths of this study consist of capturing and analysing longitudinal data from ART-naïve, HIV-seropositive participants in Botswana, which were collected from the early asymptomatic stage through defined health outcomes. During the time this study was conducted, ART initiation was at $200 \mathrm{cells} / \mu \mathrm{l}$ and it was later changed to 250 cells/ $\mu$ l following the WHO recommendations. Following the current Botswana guidelines, HIV-seropositive adults receive ART when their CD4 cell counts fall below 350 cells $/ \mu$ l. Although present WHO guidelines recommend initiation of ART at CD 4 cell count of 500 cells $/ \mu \mathrm{l}$, most countries affected by HIV have limited resources that may affect the ability to obtain this standard ${ }^{(46,47)}$. The information gathered in this study is needed and is timely as countries especially in sub-Saharan Africa are still having many challenges in providing ART and maintaining adherence ${ }^{(21)}$.

The limitations of this study include its observational nature. Moreover, with fewer participants in the higher BMI group, we were unable to examine differences between overweight and obese groups. Underweight participants were not included in the parent study, as underweight is a strong prognostic indicator of $\operatorname{AIDS}^{(21)}$. However, from the sensitivity analyses, BMI of $18-20 \mathrm{~kg} / \mathrm{m}^{2}$ was associated with significant HIV disease progression outcomes. In addition, these findings can only be generalised to HIV-seropositive patients in Africa who are not on ART. However, having information on delaying disease progression in the setting of sub-Saharan Africa is timely.

In summary, the results of this study demonstrate that higher BMI and fat mass were protective and delayed HIV disease progression among HIV-seropositive, ART-naïve adults in Botswana. Higher baseline BMI was associated with significantly lower risk of having an AIDS-defining condition. Higher fat mass at baseline was also significantly associated with a decreased risk of having AIDS-defining conditions and/or the combined outcome of having CD 4 cell count $\leq 250 / \mu \mathrm{l}$ and AIDS-defining conditions, whichever occurred earlier. Mechanistic studies on the relationship between BMI and body composition on disease progression are needed to clarify the obesity paradox in HIV.

\section{Acknowledgements}

The authors thank the participants of the study without whom advancement in the nutritional management of the HIV disease would not be possible and the Botswana-Harvard Partnership, which enabled the conduct of this study. The authors thank Jag Khalsa, PhD, Medical Consequences Branch, in the Division of Pharmacotherapies and Medical Consequences of Drug Abuse at the National Institutes on Drug Abuse, NIH, for his leadership, advice and support.

This work was supported by the National Institute on Drug Abuse (R01-DA-016551). The National Institute on Drug Abuse had no role in the design, analysis or writing of this article.
M. K. B. and R. M. had full access to all of the data in the study and take responsibility for the integrity of the data and the accuracy of the data analysis. Study concept and design: M. K. B., A. C., M. E., R. M., S. S. M.; acquisition of data: A. C., S. S. M., H. B., S. M., J. M., R. M.; analysis and interpretation of data: A. C., M. K. B., H. B., M. E., R. M.; drafting of the manuscript: S. S. M.; critical revision of the manuscript for important intellectual content: M. K. B., A. C., H. B., M. E., R. M., O. D. W., F. G. H.; statistical analysis: S. S. M., O. D. W.; obtained funding: M. K. B., A. C., M. E., R. M.; administrative, technical, or material support: M. K. B., A. C., S. S. M., J. M., M. E., R. M.; study supervision: A. C., H. B., J. M., R. M., M. K. B.

\section{References}

1. Fields-Gardner C \& Campa A, American Dietetics Association (2010) Position of the American Dietetic Association: nutrition intervention and human immunodeficiency virus infection. J Am Diet Assoc 110, 1105-1119.

2. Polsky B, Kotler D \& Steinhart C (2001) HIV-associated wasting in the HAART era. Guidelines for assessment, diagnosis, and treatment. AIDS Patient Care STDS 15, 411-423.

3. Amorosa V, Synnestvedt M, Gross R, et al. (2005) A tale of 2 epidemics: the intersection between obesity and HIV infection in Philadelphia. J Acquir Immune Defic Syndr 39, 557-561.

4. Hodgson LM, Ghattas H, Pritchitt H, et al. (2001) Wasting and obesity in HIV outpatients. AIDS 15, 2341-2342.

5. Mankal PK \& Kotler DP (2014) From wasting to obesity, changes in nutritional concerns in HIV/AIDS. Endocrinol Metab Clin North Am 43, 647-663.

6. Crum-Cianflone N, Roediger MP, Eberly L, et al. (2010) Increasing rates of obesity among HIV-Infected persons during the HIV epidemic. PLOS ONE 5, e10106.

7. Kalantar-Zadeh K, Horwich TB, Oreopoulos A, et al. (2007) Risk factor paradox in wasting diseases. Curr Opin Clin Nutr Metab Care 10, 433-442.

8. Carlson MG, Snead WL \& Campbell PJ (1994) Fuel and energy metabolism in fasting humans. Am J Clin Nutr 60, 29-36.

9. Shor-Posner G, Campa A, Zhang G, et al. (2000) When obesity is desirable: a longitudinal study of the Miami HIV-1-infected drug abusers (MIDAS) cohort. J Acquir Immune Defic Syndr 23, 81-88.

10. Gersh BJ, Sliwa K, Mayosi BM \& Yusuf S (2010) Novel therapeutic concepts: the epidemic of cardiovascular disease in the developing world: global implications. Eur Heart J 31, 642-648.

11. Uthman OA (2008) Prevalence and pattern of HIV-related malnutrition among women in sub Saharan Africa: a meta-analysis of demographic health surveys. BMC Public Health 8, 226-233.

12. Popkin BM, Adair LS \& Ng SW (2012) Global nutrition transition and the pandemic of obesity in developing countries. Nutr Rev 70, 3-21.

13. Walker AR, Adam F \& Walker BF (2001) World pandemic of obesity: the situation in Southern African populations. Public Health 115, 368-372.

14. Adeyemi OM, Vibhakar S \& Evans AT (2009) Obesity and lymphocyte subsets in virologically suppressed HIV-infected patients. Metabolism 58, 1285-1287.

15. Jones CY, Hogan JW, Snyder B, et al. (2003) Overweight and human immunodeficiency virus (HIV) progression in women: associations HIV disease progression and changes in body mass index in women in the HIV epidemiology research study cohort. Clin Infect Dis 37, S69-S80. 
16. Shuter J, Chang CJ \& Klein RS (2001) Prevalence and predictive value of overweight in an urban HIV care clinic. J Acquir Immune Defic Syndr 26, 291-297.

17. Letamo G (2011) The prevalence of, and factors associated with, overweight and obesity in Botswana. J Biosoc Sc 43, 75-84.

18. Ng M, Fleming T, Robinson M, et al. (2014) Global, regional, and national prevalence of overweight and obesity in children and adults during 1980-2013: a systematic analysis for the Global Burden of Disease Study. Lancet 30, 766-781.

19. World Bank (2011-2014) Prevalence of HIV, total (\% of population ages 15-49). http://data.worldbank.org/indicator/ SH.DYN.AIDS.ZS (accessed April 2016).

20. Bussmann H, Wester CW, Thomas A, et al. (2009) Response to zidovudine/didanosine-containing combination antiretroviral therapy among HIV-1 subtype C-infected adults in Botswana: two-year outcomes from a randomized clinical trial. J Acquir Immune Defic Syndr 51, 37-46.

21. De Cock KM \& El-Sadr WM (2013) When to start ART in Africa: an urgent research priority. $N$ Engl J Med 368, 886-889.

22. Baum MK, Campa A, Lai S, et al. (2013) Effect of micronutrient supplementation on disease progression in asymptomatic, antiretroviral-naive, HIV-infected adults in Botswana: a randomized clinical trial. JAMA 310, 2154-2163.

23. Wester CW, Koethe JR, Shepard BE, et al. (2011) NonAIDS-defining events among HIV-1 infected adults receiving combination antiretroviral therapy in resource-replete versus resource limited urban setting. AIDS 25, 1471-1479.

24. UNAIDS (2010) National AIDS Coordinating Agency (NACA) Botswana - 2010 country progress report. http:// www.unaids.ort/en/countryresponses/countries/bostwana. asp (accessed September 2014).

25. Wanke CA, Silva M, Ganda A, et al. (2003) Role of acquired immune deficiency syndrome-defining conditions in human immunodeficiency virus-associated wasting. Clin Infect Dis 37, S81-S84.

26. Taylor JM, Fahey JL, Detels R, et al. (1989) CD4 percentage, CD4 number, and CD4:CD8 ratio in HIV infection: which to choose and how to use. J Acquir Immune Defic Syndr 2, 114-124.

27. Burcham J, Marmor M, Dubin N, et al. (1991) CD $4 \%$ is the best predictor of development of AIDS in a cohort of HIV-infected homosexual men. AIDS 5, 365-372.

28. Hulgan T, Raffanti S, Kheshti A, et al. (2005) CD4 lymphocyte percentage predicts disease progression in HIV-infected patients initiating highly active antiretroviral therapy with CD4 lymphocyte counts $>350$ lymphocytes/mm3. J Infect Dis 192, 950-957.

29. Crum-Cianflone NF, Roediger M, Eberly LE, et al. (2011) Impact of weight on immune cell counts among HIV-infected persons. Clin Vaccine Immunol 18, 940-946.

30. Visnegarwala F, Raghavan SS, Mullin CM, et al. (2005) Sex differences in the associations of HIV disease characteristics and body composition in antiretroviral-naive persons. $A m J$ Clin Nutr 82, 850-856.

31. Riedel P, Ramamoorthy V, Baum MK, et al. (2014) Protein intake is associated with HIV disease progression in
HIV-infected patients. Experimental Biology 2014 Conference, San Diego, CA, 26-30 April 2014, San Diego, CA.

32. Melchior JC (1997) Metabolic aspects of HIV associated wasting. Biomed Pharmacother 51, 455-460.

33. Schaible UE \& Kaufmann SH (2007) Malnutrition and infection: complex mechanisms and global impacts. PLoS Med $\mathbf{4}$, e115.

34. Scrimshaw NS \& SanGiovanni JP (1997) Synergism of nutrition, infection, and immunity: an overview. Am J Clin Nutr $\mathbf{6 6}$, 464S-477S

35. Chandra RK (1997) Nutrition and the immune system: an introduction. Am J Clin Nutr 66, 460S-463S.

36. Koethe JR, Hulgan T \& Niswender K (2013) Adipose tissue and immune function: a review of evidence relevant to HIV infection. J Infect Dis 208, 1194-1201.

37. Berdanier CD (1998) CRC Desk Reference for Nutrition. Boca Raton, FL: CRC Press.

38. Koethe JR, Jenkins CA, Lau B, et al. (2015) Body mass index and early CD4 T-cell recovery among adults initiating antiretroviral therapy in North America, 1998-2010. HIV Med 16, 572-577.

39. McGee DL, Diverse Populations Collaboration (2005) Body mass index and mortality: a meta-analysis based on person-level data from twenty-six observational studies. Ann Epidemiol 15, 87-97.

40. Bogers RP, Bemelmans WJ, Hoogenveen RT, et al. (2007) Association of overweight with increased risk of coronary heart disease partly independent of blood pressure and cholesterol levels: a meta-analysis of 21 cohort studies including more than 300000 persons. Arch Intern Med 167, $1720-1728$

41. Sullivan PW, Morrato EH, Ghushchyan V, et al. (2005) Obesity, inactivity, and the prevalence of diabetes and diabetes-related cardiovascular comorbidities in the U.S., 2000-2002. Diabetes Care 28, 1599-1603.

42. Calle EE, Rodriguez C, Walker-Thurmond K, et al. (2003) Overweight, obesity, and mortality from cancer in a prospectively studied cohort of U.S. adults. $N$ Engl J Med 348, $1625-1638$

43. Stevens J, Bradshaw PT, Truesdale KP, et al. (2015) Obesity Paradox should not interfere with public health efforts. Int J Obes (Lond) 39, 80-81.

44. Dixon JB, Egger GJ, Finkelstein EA, et al. (2015) 'Obesity paradox' misunderstands the biology of optimal weight throughout the life cycle. Int J Obes (Lond) 39, 82-84.

45. Fields-Gardner C \& Campa A, American Dietetic Association (2010) Position of the American Dietetic Association: nutrition intervention and human immunodeficiency virus infection. I Am Diet Assoc 110, 1105-1119.

46. World Health Organization (2013) WHO issues new HIV recommendations calling for earlier treatment. World Health Organization news release. http://www.who.int/mediacentre/ news/releases/2013/new_hiv_recommendations_20130630/en/ (accessed November 2015).

47. Piot P \& Quinn TC (2013) Response to the AIDS pandemic: a global health model. $N$ Engl J Med 368, 2210-2218. 